\title{
European Cardiovascular Magnetic Resonance (EuroCMR) registry - multi national tesults from 57 centers in 15 countries
}

Anja Wagner ${ }^{1 *}$, Oliver Bruder ${ }^{2}$, Massimo Lombardi ${ }^{3}$, Juerg Schwitter ${ }^{4}$, Albert C van Rossum ${ }^{5}$, Guenter Pilz $^{6}$, Detlev Nothnagel ${ }^{7}$, Steffen E Petersen ${ }^{8}$, Eike Nagel ${ }^{9}$, Sanjay K Prasad ${ }^{10}$, Herbert Frank ${ }^{12}$, Thorsten Dill ${ }^{11}$, Steffen Schneider ${ }^{13}$, Heiko Mahrholdt ${ }^{14}$

From 16th Annual SCMR Scientific Sessions

San Francisco, CA, USA. 31 January - 3 February 2013

\section{Background}

The EuroCMR registry determined indications, image quality, safety and impact on patient management of clinical routine CMR in a multi-national European setting.

Furthermore, interim analyses of two specific protocols evaluating the prognostic potential of CMR in patients with coronary artery disease (CAD) and hypertrophic cardiomyopathy $(\mathrm{HCM})$ are presented.

\section{Methods}

Multi-center registry with consecutive enrollment of patients in 57 centers in 15 countries [1].

\section{Results}

27,781 patients were enrolled. The most frequent indications were risk stratification in CAD/ischemia (34.2\%), workup of cardiomyopathies (32.2\%) and assessment of viability (14.6\%). Image quality was diagnostic in $98 \%$. Severe complications were rare $(0.03 \%)$.

In $61.8 \%$ CMR findings had an impact on patient management. In $8.7 \%$ the final diagnosis changed based on CMR findings (Table 1).

Kaplan-Meier survival curves of the interim analyses showed low adverse event rates in patients with suspected CAD with a normal stress CMR (1.0\% per year), and in $\mathrm{HCM}$ without delayed enhancement $(2.7 \%$ per year).

\section{Conclusions}

The most important CMR indications in Europe are risk stratification in suspected CAD/ischemia, work-up of cardiomyopathies and assessment of viability. CMR is a safe procedure, has diagnostic image quality in more than $98 \%$ of cases, and its results have a strong impact on patient management. Interim analyses underscore the prognostic value of clinical routine CMR in patients with CAD and HCM.

\section{Funding}

Medtronic Inc., Minneapolis MN, USA.

Novartis International AG, Basel, Switzerland.

Siemens Health Care, Erlangen, Germany.

Table 1 Impact of CMR on patient management by indication

\begin{tabular}{cccc}
\hline & $\begin{array}{c}\text { Myocarditis/ } \\
\text { Cardiomyopathy }\end{array}$ & $\begin{array}{c}\text { Suspected } \\
\text { CAD/ } \\
\text { Ischemia }\end{array}$ & Viability \\
\hline All (from $n=27781)$ & $32.2 \%$ & $34.2 \%$ & $14.6 \%$ \\
New diagnosis & $11.4 \%$ & $8.1 \%$ & $5.3 \%$ \\
Therapeutic consequences: & & & \\
Change in medication & $25.3 \%$ & $24.3 \%$ & $33.2 \%$ \\
Invasive procedure & $6.9 \%$ & $23.1 \%$ & $24.2 \%$ \\
Hospital discharge & $10.4 \%$ & $14.3 \%$ & $6.9 \%$ \\
Impact on patient & $55.1 \%$ & $71.4 \%$ & $71.5 \%$ \\
management (new diagnosis & & & \\
and/or therapeutic & & & \\
consequence) & & &
\end{tabular}

${ }^{1}$ Cardiology, Comprehensive Cardiology, Stamford, CT, USA

Full list of author information is available at the end of the article

(c) 2013 Wagner et al; licensee BioMed Central Ltd. This is an Open Access article distributed under the terms of the Creative Commons Attribution License (http://creativecommons.org/licenses/by/2.0), which permits unrestricted use, distribution, and reproduction in any medium, provided the original work is properly cited. 


\section{Author details}

${ }^{1}$ Cardiology, Comprehensive Cardiology, Stamford, CT, USA. ${ }^{2}$ Cardiology,

Contilia Heart and Vascular Center, Essen, Germany. ${ }^{3}$ Cardiology, C.N.R.J

Regione Toscana "G. Monasterio Foundation", Pisa, Italy. ${ }^{4}$ Cardiology, Cardiac MR Centre, University Hospital (CHUV) Lausanne, Lausanne, Switzerland.

${ }^{5}$ Cardiology, VU Medical Centre, Amsterdam, Netherlands. ${ }^{6}$ Cardiology,

Hospital Agatharied, Hausham, Germany. ${ }^{7}$ Cardiology, Klinikum Ludwigsburg,

Ludwigsburg, Germany. ${ }^{8}$ Barts and The London NIHR Biomedical Research

Unit, The London Chest Hospital, London, UK. 'Division of Imaging Sciences,

King's College London BHF, London, UK. ${ }^{10} \mathrm{CMR}$ Unit, Royal Brompton

Hospital, London, UK. ${ }^{11}$ Internal Medicine, Krankenhaus Benrath, Düsseldorf,

Germany. ${ }^{12}$ Cardiology, Donauklinikum Tulln, Tulln, Austria. ${ }^{13}$ Department of

Statistics, Institut für Herzinfarktforschung, Ludwigshafen, Germany.

${ }^{14}$ Cardiology, Robert Bosch Medical Center, Stuttgart, Germany.

Published: 30 January 2013

\section{Reference}

1. Wagner A, et al.. J Cardiovasc Magn Resn 2009.

doi:10.1186/1532-429X-15-S1-096

Cite this article as: Wagner et al:: European Cardiovascular Magnetic

Resonance (EuroCMR) registry - multi national tesults from 57 centers

in 15 countries. Journal of Cardiovascular Magnetic Resonance 201315

(Suppl 1):096.

\section{Submit your next manuscript to BioMed Central} and take full advantage of:

- Convenient online submission

- Thorough peer review

- No space constraints or color figure charges

- Immediate publication on acceptance

- Inclusion in PubMed, CAS, Scopus and Google Scholar

- Research which is freely available for redistribution

Submit your manuscript at www.biomedcentral.com/submit 